L'éducation à l'information, aux TIC et aux médias : le temps de la convergence?

\title{
Philippe Bouquillion, Jacob T. Matthews : Le Web collaboratif. Mutations des industries de la culture et de la communication
}

\section{Sami Ben Balaïd}

\section{OpenEdition}

\section{Journals}

Édition électronique

URL : http://journals.openedition.org/edc/3447

DOI : 10.4000/edc.3447

ISSN : 2101-0366

\section{Éditeur}

Université de Lille

Édition imprimée

Date de publication : 30 juin 2012

Pagination : 217-219

ISBN : 978-2-917562-07-9

ISSN : $1270-6841$

\section{Référence électronique}

Sami Ben Balaïd, «Philippe Bouquillion, Jacob T. Matthews : Le Web collaboratif. Mutations des industries de la culture et de la communication ", Études de communication [En ligne], 38 | 2012, mis en ligne le 01 janvier 2012, consulté le 21 septembre 2020. URL : http://journals.openedition.org/edc/ 3447 ; DOI : https://doi.org/10.4000/edc.3447

Ce document a été généré automatiquement le 21 septembre 2020

() Tous droits réservés 


\title{
Philippe Bouquillion, Jacob T. Matthews : Le Web collaboratif. Mutations des industries de la culture et de la communication
}

\author{
Sami Ben Balaïd
}

\section{RÉFÉRENCE}

Philippe Bouquillion, Jacob T. Matthews, Le Web collaboratif. Mutations des industries de la culture et de la communication, Grenoble, PUG, Collection, La Communication en plus,

152 pages, 2010

1 Cet ouvrage se propose de questionner le Web collaboratif sous différents angles: hétérogénéité des modèles socio-économiques, ses rapports avec les mutations des industries de la culture et de la communication, sa participation à la légitimation du capitalisme, sa contribution à la construction des rapports sociaux et les enjeux qu'il pose aux sciences humaines et sociales. Le premier chapitre de l'ouvrage s'intéresse donc aux modèles socio-économiques englobés par le Web collaboratif: les auteurs reviennent sur les différentes sources de financement pour distinguer les entreprises, comme l'innovation liée aux contenus (premium et générés par les usagers), les partenariats réalisés avec les distributeurs traditionnels issus des industries de la culture, la publicité, la franchisation d'un concept et d'un dispositif technique et la mise en place et l'entretien de solutions techniques internes. Ils complètent ces distinctions économiques par les représentations que se font les entreprises étudiées d'elles-mêmes, et montrent qu'il y a confusion dans la définition de leur spécificité, hormis concernant la mise en avant de leur agilité et de leur réactivité, ainsi que la rupture revendiquée du mode d'accès aux contenus, vue comme la naissance d'un nouveau modèle. Les auteurs relèvent donc les contours d'une démarche nouvelle : la création d'outils et la mise en retrait de ces acteurs qui se voient comme des 
«facilitateurs» pour des usagers créateurs de contenus. Dans un second chapitre, les auteurs commencent par rappeler les frontières poreuses entre vie publique et vie privatique depuis la liaison médias/produits de consommation, pour ensuite évoquer le mouvement de culturalisation de l'économie appuyé par le Web 2.0, qui aurait comme conséquence le brouillage entre objets culturels et produits de consommation, et comme cause, une utilisation particulière des contenus: ces derniers attirent des usagers, qui attirent à leur tour des financeurs. Cette logique place les entreprises du Web 2.0 dans une position dominante de "point de rencontre obligé ». Cette mutation néo-industrielle aurait pour finalité un mouvement des contenus au centre des cycles de production de produits commerciaux, et l'inclusion du consommateur-créateur dans ces cycles, avec pour conséquence l'affaiblissement de la valeur symbolique du culturel. Le troisième chapitre de l'ouvrage est dédié au rôle du Web collaboratif dans la légitimation du capitalisme. Ainsi, les auteurs y traitent les questions de la libre appropriation des contenus, de la mise en avant de l'amateur-créateur et du recul des stratégies des industries culturelles. Tout ceci mènerait à la construction idéologique d'une nouvelle économie collaborative, et le choix et la maitrise étant entre les mains des consommateurs, à une forme moderne du capitalisme. Les auteurs proposent comme origine de cette construction un mouvement de convergence, indissociable de la culture participative et de l'intelligence collective, et issu de la culture fan. Il s'agit, à terme, de voir l'émergence d'un statut nouveau du consommateur dans une société postindustrielle proche de l'homme-média. Du côté des acteurs de l'économie, on constate un engagement dans une affective economy, dont le but premier serait de provoquer l'engagement émotionnel chez des fans participant à la construction de la marque. Les médias sont donc jugés selon leur capacité à provoquer l'investissement personnel des usagers. Au cours du quatrième chapitre, les auteurs relèvent que dans les discours sur le Web collaboratif, circule une conception latente de l'individu qui se réaliserait à travers les mondes virtuels si ses besoins ne sont pas satisfaits dans un contexte immédiat. Il s'agit pour ces discours de souligner un "potentiel émancipateur » du web collaboratif, qui offre en réalité la possibilité aux usagers de produire une illusion d'émancipation. La source et la finalité des communautés du Web 2.0 seraient donc l'activisme bienheureux de ses membres, réunis sur des préférences, des pratiques culturelles ou sur la base d'une utilisation d'un même média, avec comme bénéfice une amélioration du fonctionnement de la société : le rôle du Web 2.0 serait donc celui d'une vitrine de l'altérité et de la diversité mais également celui d'un vecteur de cohérence sociale. Les auteurs questionnent cette utopie en proposant l'hypothèse de la ghettoïsation et de la normalisation des différences à l'affirmation universelle de la participation au réseau comme nécessité à l'épanouissement individuel. Dans cette optique, le Web 2.0 semble profiter d'abord aux acteurs capitalistes, qui peuvent faire coexister la logique de surveillance (collecte de données marketing) et l'empowerment des usagers-créateurs. Les auteurs montrent également dans les discours la considération du web collaboratif comme un champ d'expérimentation sociale in vitro, sans médiation, avec un cadre neutre à disposition des usagers. Il conviendrait selon l'ouvrage de reconsidérer l'action des entreprises, et la tentative de naturalisation du social que sont ces discours. Ces discours tenteraient de bâtir un "sujet " global dont l'analyse révèle qu'il nie les inégalités sociales, les conflits, et gomme les sources visibles de domination. Le dernier chapitre de cet ouvrage s'intéresse aux injonctions lancées aux Sciences Humaines et Sociales dans les discours du Web collaboratif, notamment par Henry Jenkins, qui suppose la réalisation 
d'une utopie à travers le Web collaboratif : la société en réseau place le fan au cœur du politique, faisant de la nation un ensemble de communautés qui négocient grâce au politique, directement ou indirectement. De ce fait, la critique académique ne serait pas pertinente et irait contre l'Histoire qui supporterait une industrie culturelle globale. Jenkins invite au contraire les universitaires à devenir des « acteurs-réseaux » entre les différents groupes actant pour la culture participative, et à agir pour l'amélioration du système. Les auteurs reviennent sur l'origine de cette pensée, à savoir la croyance en la renaissance d'une culture folk fantasmatique, et en l'imaginaire social comme moteur de transformation de l'industrie culturelle globale, avant de proposer d'œuvrer, au contraire, à l'autonomie des discours scientifiques sur le Web collaboratif en interrogeant par exemple la subjectivité individuelle dans l'usage des réseaux.

2 Cet ouvrage concis éclaire de manière complète la question et les enjeux du Web collaboratif : reliant la problématique à des questionnements plus vastes, le travail des auteurs permet de replacer le Web collaboratif dans un contexte global et de saisir les tenants et aboutissants d'un monde qui semble, a priori, déconnecté et indépendant.

\section{AUTEURS}

\section{SAMI BEN BALAÏD}

M2 SCCD - Université de Lille 3 